\title{
Laboratoryjne badania akustyczne skał pod kątem potrzeb hydraulicznego szczelinowania
}

\begin{abstract}
Niniejsza praca przedstawia wstępne wyniki badań laboratoryjnych dynamicznych parametrów sprężystości z wybranych polskich złóż węglowodorów. Do analiz zostały wybrane trzy próbki rdzeniowe: dolomit oraz dwa rodzaje piaskowca różniące się zawartością minerałów ilastych. Badania wykonano w warunkach odpowiadających tym, które panują w odwiercie. Zostały przeprowadzone symulacje zmian ciśnienia nadkładu, ciśnienia efektywnego i temperatury tak, aby zaobserwować ich wpływ na prędkość fal akustycznych P i S. Do przestrzeni porowej jednej z próbek zatłaczano media o zbliżonej gęstości i lepkości: solankę $2 \% \mathrm{KCl}$ oraz „martwą”, lekką ropę naftową. Zaobserwowano przewidywany wzrost prędkości fal wraz ze wzrostem ciśnienia efektywnego i spadek prędkości wraz ze wzrostem temperatury, a także zmiany prędkości fal spowodowane obecnością mediów porowych. Zostały wyznaczone stałe sprężystości: współczynnik Poissona oraz moduł Younga. Uzyskane wyniki odniesiono do danych literaturowych. Sformułowano również wstępne wnioski dotyczące podatności badanych skał na zabiegi hydraulicznego szczelinowania.
\end{abstract}

Słowa kluczowe: geomechanika, geoakustyka, dynamiczne współczynniki sprężystości, hydrauliczne szczelinowanie.

\section{Laboratory acoustic measurements for the needs of hydraulic fracturing}

This paper presents the preliminary results of the laboratory measurements of the dynamic elasticity modules. The measurements were performed on selected Polish hydrocarbon reservoir rocks. Three core samples were chosen: dolomite and two types of sandstones which differed in the amount of clay minerals. The tests were performed under simulated reservoir conditions. During measurements, the simulations of the overburden pressure, effective pressure and temperature changes, were conducted in order to observe their influence on the velocities of the $\mathrm{P}$ and $\mathrm{S}$ waves. The studies of one of the samples were carried out on dry and saturated by $2 \% \mathrm{KCl}$ brine and light dead oil. Both of these liquids had similar density and viscosity. Expected changes in velocity caused by changes of pressure, temperature and type of pore fluid were observed. Poisson's and Young's ratio, were calculated. The results were related to the data available in the literature. Finally, preliminary conclusions, concerning the susceptibility of the studied rocks to hydraulic fracturing treatment were formulated.

Key words: geomechanics, laboratory acoustic measurements, dynamic elastic moduli, hydraulic fracturing.

\section{Wstęp}

W dzisiejszych czasach laboratoryjne badania geoakustyczne są coraz częściej wykorzystywane w inżynierii naftowej. Są to testy nieniszczące, pozwalające precyzyjnie wyznaczać dynamiczne moduły sprężystości skał [11, 12]. Obecny rozwój aparatury badawczej umożliwia wykonywanie badań tego rodzaju na próbkach rdzeniowych nasyconych mediami złożowymi, w symulowanych warunkach ciśnienia oraz temperatury złożowej $[1,8,21,23,27,28]$. Analizy te można więc $\mathrm{w}$ prosty sposób odnieść do warunków złożowych. Mogą one stanowić uzupełnienie danych pozyskiwanych za pomocą profilowań geofizyki otworowej lub, w przypadku ich braku, podstawę w procesie projektowania geometrii szczeliny dla potrzeb zabiegów hydraulicznego szczelinowania.

Informacje na temat geomechaniki skały złożowej oraz skał otaczających często stanowią o powodzeniu lub porażce zabiegu szczelinowania. Pozwalają one określić podatność skały na szczelinowanie i stopień jej kruchości lub plastyczności [15, 17, 19, 24]. Dzięki nim można modelować długość oraz rozwartość projektowanej szczeliny tak, aby dopasować 
ją do konkretnej sytuacji złożowej $[9,13,18]$. Na podstawie danych geomechanicznych dobierane są odpowiednie płyny zabiegowe: bardziej lepkie dla skał plastycznych, mniej dla skał kruchych (rysunek 1) [10]. Od lepkości płynu, determinującej jego właściwości transportowe, zależy rodzaj stosowanego materiału podsadzkowego, a także prędkość zatłaczania samego płynu oraz ciśnienie tłoczenia.
Celem niniejszej pracy było określenie dynamicznych modułów sprężystości dla próbek z wybranych polskich złóż węglowodorów oraz wyznaczenie zależności między zmianami symulowanych warunków in situ a zmianami wartości modułów sprężystości. Dodatkowym celem było udoskonalenie metodyki pomiarów oraz lepsze poznanie możliwości urządzenia do prowadzenia badań geomechanicznych AVS-700.

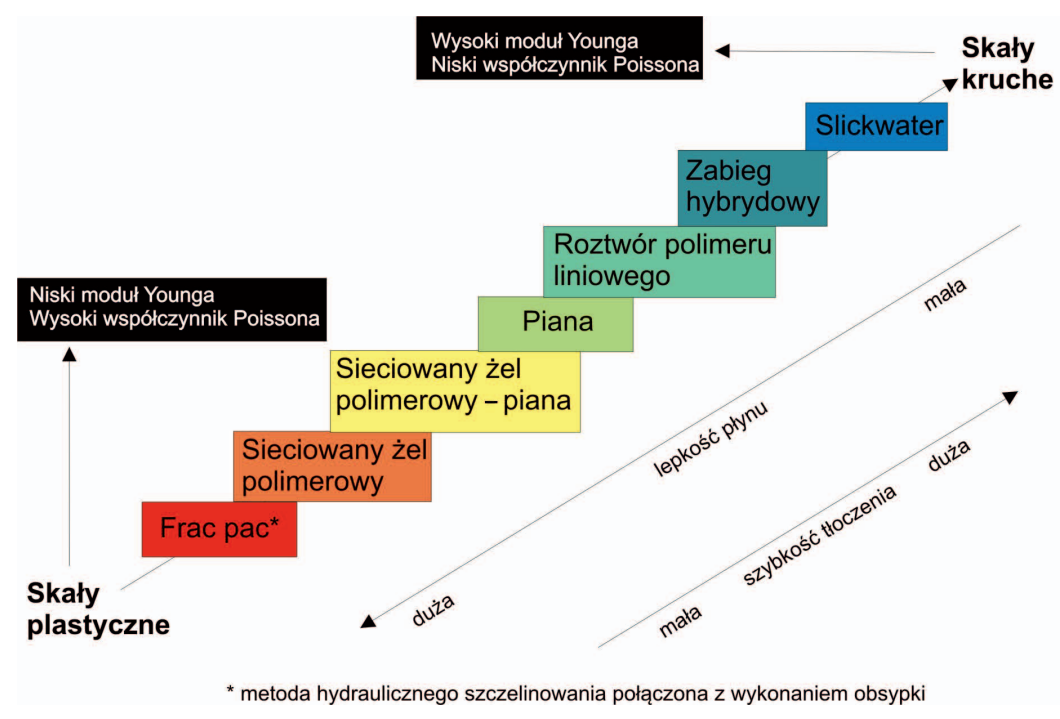

Rys. 1. Powiązanie właściwości mechanicznych skały złożowej z rodzajami płynów szczelinujących [10, zmodyfikowane]

\section{Właściwości sprężyste skał - badania in situ i laboratoryjne}

Parametry mechaniczne (moduły sprężystości) można uzyskać za pomocą profilowań akustycznych geofizyki otworowej oraz laboratoryjnych badań geoakustycznych lub wytrzymałościowych.

Profilowania akustyczne geofizyki otworowej są od wielu lat szeroko stosowane w odwiertach naftowych [29]. Dzięki specyfice technologii (profilowanie klasyczne na kablu oraz profilowanie LWD) możliwe jest wyznaczenie dynamicznych parametrów sprężystości dla skał na całej długości interesującego odcinka w odwiercie $[14,20,22]$. Ponieważ pomiary wykonuje się in situ, w temperaturze złożowej oraz w ciśnieniu złożowym, ich dokładność jest wysoka. Jednak ich rozdzielczość pionowa zależy od rodzaju używanych sond (długość fali) oraz typu pomiaru, więc może być w pewnych przypadkach niezadowalająca.

Badania laboratoryjne na rdzeniach wiertniczych odznaczają się tym, że dane uzyskiwane za ich pomocą mają charakter punktowy. Badane są fragmenty rdzeni, długości kilku/kilkunastu centymetrów, z najbardziej interesujących części odwiertu (sweet spot) lub ze skał otaczających. Za pomocą badań laboratoryjnych można uzyskać parametry sprężystości statyczne (badania wytrzymałościowe, testy zniszczeniowe) oraz dynamiczne (badania geoakustyczne) [11, 12].
Przewagą badań laboratoryjnych, w szczególności geoakustycznych, jest fakt, że przez znajomość rodzaju skały, z której wykonana jest próbka (dokładnego składu mineralogicznego, składu medium wypełniającego pory), a także jej wymiarów, można bardzo precyzyjnie wyznaczyć dynamiczne moduły sprężystości. Dzięki nowoczesnym urządzeniom pozwalającym wykonywać badania w układzie konwencjonalnego, trójosiowego ściskania w temperaturze złożowej, możliwe jest symulowanie warunków in situ podczas pomiarów. Akustyczne badania laboratoryjne są stosunkowo tanie i mogą być dobrym uzupełnieniem profilowań geofizyki otworowej lub - w razie braku danych geofizycznych albo ich niskiej jakości - stanowić podstawę do tworzenia modeli propagacji szczelin w złożu.

Zarówno podczas pomiarów in situ, jak i laboratoryjnych nieznana jest dokładna droga, jaką przebywa propagująca fala. Należy założyć, że ze względu na anizotropię w skład promienia falowego wejdzie nieskończona ilość części, z której każda będzie odpowiadała najmniejszej nawet zmianie gęstości ośrodka, ciśnienia, temperatury i innych parametrów.

W przypadku badań laboratoryjnych, w sytuacji, gdy jest dostępna niewielka próbka rdzeniowa, której wymiary (waga, gęstość, porowatość oraz przepuszczalność) są dokładnie zna- 
ne, można „z góry” spodziewać się pewnych wyników oraz dynamicznie, w trakcie trwania pomiarów, weryfikować poprawność obliczeń i korygować czasy pierwszych wstąpień fal. Natomiast podczas badań akustycznych in situ interesujący obszar jest nieporównywalnie większy, a cechy, którymi charakteryzują się skały, są wyznaczane dzięki profilo- waniom geofizyki otworowej. To sprawia, że obszar ten nie jest tak precyzyjnie określony jak w przypadku badań laboratoryjnych. Zmiany parametrów ośrodka, takie jak np. niewielkie przeławicenia piaskowców w warstwach łupków bitumicznych, mogą być niewystarczająco dokładnie widoczne i przez to nie do końca poprawnie interpretowane.

\section{Metodyka badań}

Do badań wybrano trzy rodzaje skał z polskich złóż węglowodorów:

- próbka 1 -skała węglanowa, dolomit cechsztyński. Jest to skała drobnoziarnista posiadająca w składzie mineralnym przewagę węglanu wapnia nad pozostałymi składnikami. Jest skałą zbiornikową w jednym z największych polskich złóż węglowodorów. Tego rodzaju skały są wykorzystywane do badań przepływowych na rdzeniach wiertniczych;

- próbka 2 - skała piaskowcowa kredy górnej o wysokiej zawartości minerałów ilastych, o spoiwie ilasto-węglanowym. Piaskowiec charakteryzuje się frakcją drobnoziarnistą oraz wysoką zawartością minerałów ilastych. Zawartość minerałów węglanowych nie przekracza kilku do kilkunastu procent;

- próbka 3 - piaskowiec czerwonego spągowca. Skała o charakterystycznej czerwonawej barwie, pochodzacej od zawartych w niej związków żelaza. Jest piaskowcem średnioziarnistym o wysokiej zawartości $\mathrm{SiO}_{2}$.

Z powyższych skał zostały wycięte próbki rdzeniowe o średnicy 1 cala i długości, w zależności od możliwości, od 1 do 3 cali. Każda z próbek została przebadana pod kątem porowatości przy użyciu porozymetru helowego HPG-100 oraz przepuszczalności na przepuszczalnościomierzu DGP-100. Porowatość efektywną, przepuszczalność i gęstość objętościową dla próbek podano w tablicy 1 .

Do przestrzeni porowej trzeciej próbki zatłaczano media złożowe. Na potrzeby niniejszych badań zostały wybrane dwa media złożowe:
- solanka $2 \% \mathrm{KCl}$, wykonana laboratoryjnie, o gęstości $1 \mathrm{~g} / \mathrm{cm}^{3}$ oraz lepkości $0,89 \mathrm{cP}$,

- ropa naftowa „martwa” (odgazowana), lekka (o niewielkiej zawartości węglowodorów ciężkich), niezasiarczona, z jednego z podkarpackich złóż, o gęstości $0,83 \mathrm{~g} / \mathrm{cm}^{3}$ i lepkości 2 cP.

Badania przeprowadzano na urządzeniu AVS-700, jednym z najnowocześniejszych, stacjonarnych zestawów do pomiarów dynamicznych modułów sprężystości próbek skał w warunkach symulujących warunki złożowe (rysunek 2). Urządzenie posiada trójosiową komorę rdzeniową, dzięki czemu umożliwia pomiar właściwości mechanicznych skał podczas konwencjonalnego, trójosiowego ściskania, układ umożliwiający zatłoczenie medium złożowego do przestrzeni porowej rdzenia pod ciśnieniem oraz płaszcz grzewczy. AVS-700 pozwala wyznaczać czasy przejścia fal P i S przez próbkę rdzeniową i na tej podstawie zostały obliczone prędkości fal oraz moduły geomechaniczne: moduł Younga $(E)$ i współczynnik Poissona (v). Dla każdej z próbek wykonano cykl pomiarów ( $10 \div 14$ pomiarów), w zmiennych warunkach ciśnienia uszczelnienia i temperatury oraz (w przypadku próbki 3) przy przestrzeni porowej nasyconej powietrzem, solanką lub „martwą” ropą. Obrazy falowe zostały zarejestrowane w formie cyfrowego wykresu amplitudy od czasu. Głowice aparatury pracowały przy częstotliwości $500 \mathrm{kHz}$.

Dokładność uzyskanych parametrów na urządzeniu została opisana w tablicy 2.

Tablica 1. Wybrane właściwości badanych próbek

\begin{tabular}{|l|c|c|c|}
\hline \multicolumn{1}{|c|}{ Próbka } & $\begin{array}{c}\text { Porowatość efektywna } \\
{[\%]}\end{array}$ & $\begin{array}{c}\text { Przepuszczalność } \\
{[\mathrm{mD}]}\end{array}$ & $\begin{array}{c}\text { Gęstość objętościowa } \\
{\left[\mathrm{g} / \mathrm{cm}^{3}\right]}\end{array}$ \\
\hline 1. Dolomit cechsztyński & 18,42 & 3,78 & 2,22 \\
\hline 2. Piaskowiec kredy górnej & 1,58 & 0,42 & 2,61 \\
\hline 3. Piaskowiec czerwonego spągowca & 16,40 & 8,40 & 2,17 \\
\hline
\end{tabular}

Tablica 2. Dokładność uzyskiwanych wyników podczas badań na urządzeniu AVS-700

\begin{tabular}{|c|c|c|c|c|c|c|}
\hline Parametr & Temperatura $(T)$ & Ciśnienie $(p)$ & $\begin{array}{c}\text { Czas propagacji } \\
\text { fal }(t)\end{array}$ & $\begin{array}{c}\text { Prędkość } \\
\text { propagacji }(V)\end{array}$ & $\begin{array}{c}\text { Współczynnik } \\
\text { Poissona }(v)\end{array}$ & $\begin{array}{c}\text { Moduł } \\
\text { Younga }(E)\end{array}$ \\
\hline Dokładność do: & $0,1^{\circ}$ & $1 \mathrm{psi}$ & $0,1 \mu \mathrm{s}$ & $1 \mathrm{~m} / \mathrm{s}$ & $0,01[-]$ & $0,1 \mathrm{GPa}$ \\
\hline
\end{tabular}




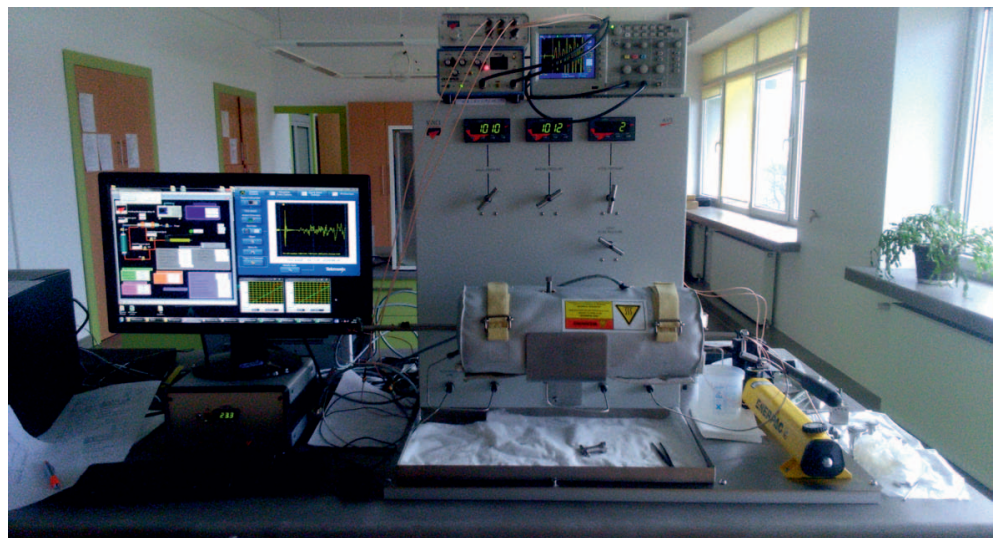

Rys. 2. Urządzenie AVS-700

\section{Wyniki badań oraz dyskusja}

\section{Próbka 1 - dolomit cechsztyński}

Pomiary z użyciem próbki 1 były wykonywane w stanie suchym. W pierwszym kroku w temperaturze pokojowej stopniowo podnoszono ciśnienie uszczelnienia od 0 do 2000 psi, a następnie $\mathrm{w}$ drugim kroku przy stałym ciśnieniu uszczelnienia 2000 psi podwyższano temperaturę próbki do $115^{\circ} \mathrm{C}$.

W pierwszym etapie prędkość fali P zawiera się, w zależności od ciśnienia uszczelnienia, w przedziale od 3294 do $3554 \mathrm{~m} / \mathrm{s}$, a prędkość fali S wynosi od 1890 do $2068 \mathrm{~m} / \mathrm{s}$ (rysunek 3). Współczynnik porowatości efektywnej rzędu 18\% powoduje, że przestrzeń porowa próbki jest w dużej mierze wypełniona gazem (powietrzem) wpływającym na obniżenie prędkości fal akustycznych, a w szczególności fali P, jak opisuje M. Bała [2]. Stosunek $V_{p} / V_{s}$ waha się w granicach $1,66 \div 1,72$. Wysoka zawartość gazu w przestrzeni porowej wpływa także na obniżenie modułów sprężystości, ponieważ powietrze posiada o wiele niższe niż skała moduły $k$ oraz $\mu$ [26]. Współczynnik Poissona zawiera się w przedziale $0,2 \div 0,25$ (rysunek 4), podczas gdy moduł Younga oscyluje pomiędzy $25 \div 30 \mathrm{GPa}$ (rysunek 5). Są to wartości niższe od wartości prezentowanych przez M. Bałę [2] dla zbi-

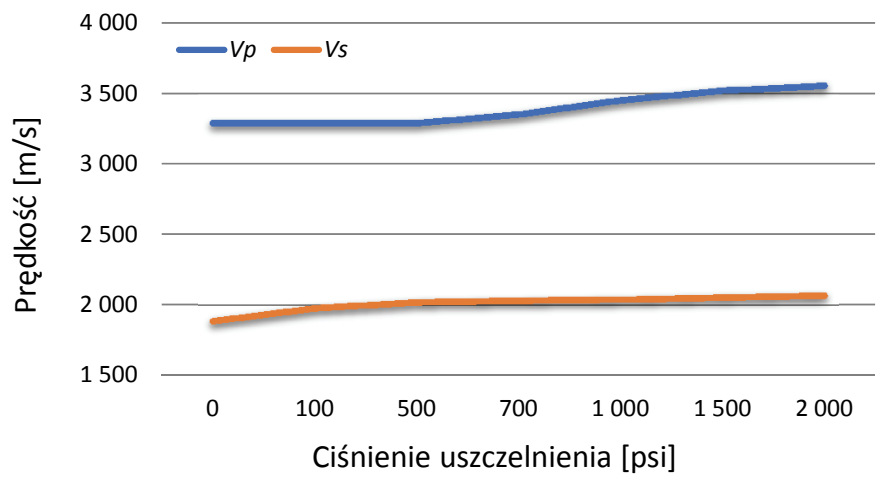

Rys. 3. Zmiany prędkości fal P i S w zależności od zmian ciśnienia uszczelnienia. Próbka 1 - dolomit cechsztyński. Temperatura $=24^{\circ} \mathrm{C}$ tych dolomitów cechsztyńskich z otworu KG-1 (tablica 3). Wraz ze wzrostem ciśnienia uszczelnienia można zaobserwować zwiększenie prędkości fal P i S oraz wzrost modułów $v$ i $E$ (rysunki 3-5).

W drugim etapie wzrost temperatury pomiaru powoduje spadek prędkości fal P i S: do $3294 \mathrm{~m} / \mathrm{s}$ dla fali P i do $1969 \mathrm{~m} / \mathrm{s}$ dla fali S (rysunek 6), co pociąga za sobą spadek wartości modułów sprężystości. Zjawisko to potwierdzają dane literaturowe [8].

W kontekście zabiegu szczelinowania w badanej skale można ocenić, że jest ona średnio podatna na szczelinowanie. Moduł $E$ oraz współczynnik $v$ sugerują, że skała jest dość plastyczna, przez co szczelina wytworzona w niej podczas zabiegu prawdopodobnie wykazywałyby niewielki stopień skomplikowania. Koncentracja materiału podsadzkowego w czasie zabiegu musiałaby być stosunkowo wysoka, a objętość cieczy niewielka. Aby lepiej ocenić podatność skały na hydrauliczne szczelinowanie lub szczelinowanie kwasem, należałoby w przyszłości wyznaczyć parametr kruchości w sposób, który opisują B. Grieser i J. Bray [15] oraz R. Rickman i inni [24].

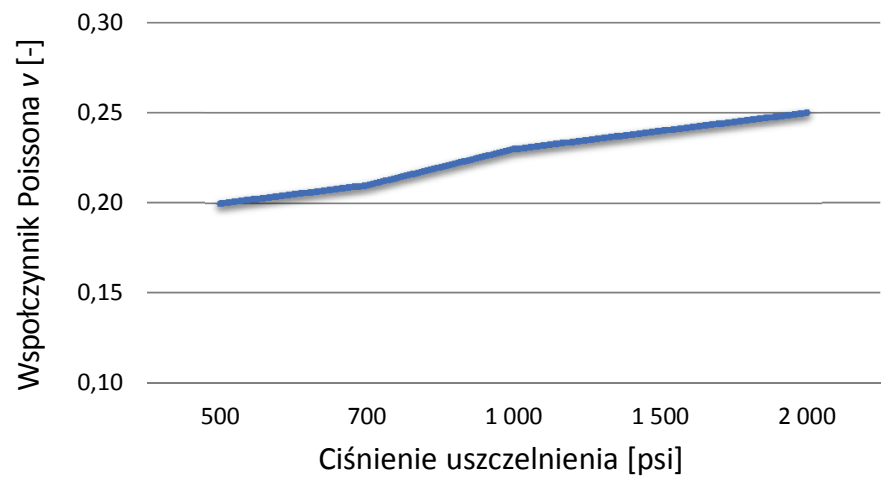

Rys. 4. Zmiany wartości współczynnika Poissona w zależności od zmian ciśnienia uszczelnienia. Próbka $1-$ dolomit cechsztyński. Temperatura $=24^{\circ} \mathrm{C}$ 


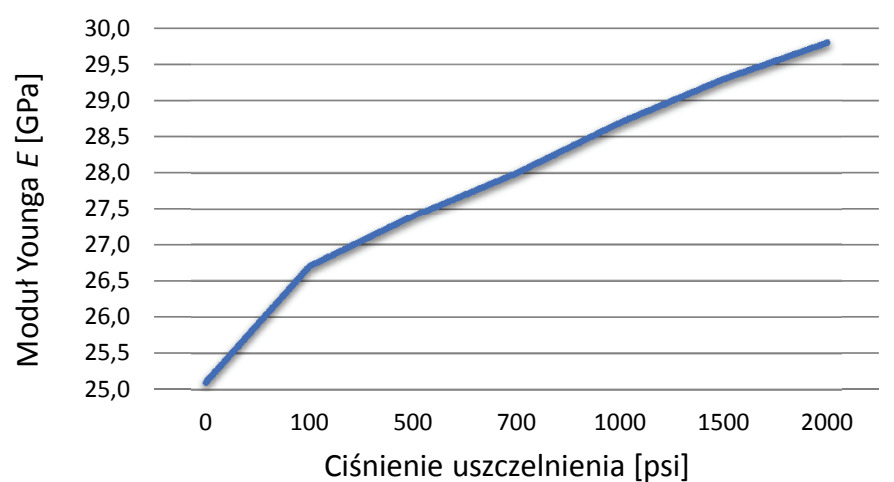

Rys. 5. Zmiany wartości modułu Younga w zależności od zmian ciśnienia uszczelnienia. Próbka 1 - dolomit cechsztyński. Temperatura $=24^{\circ} \mathrm{C}$

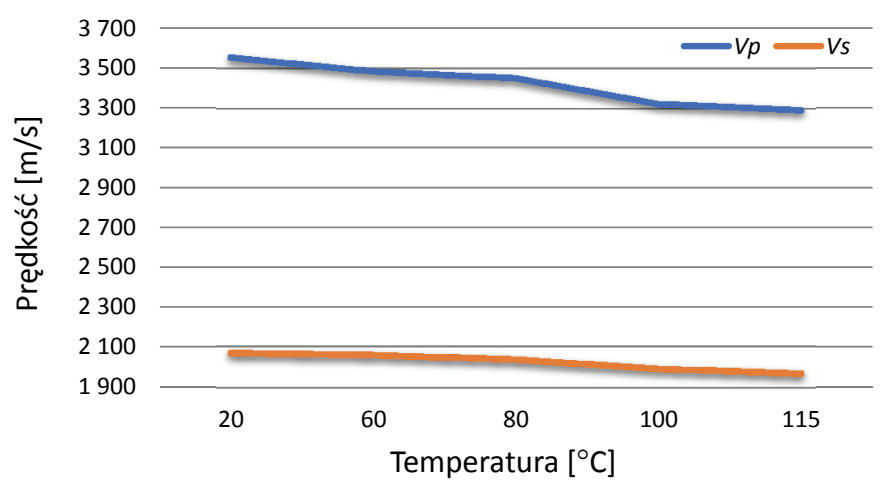

Rys. 6. Zmiany prędkości fal P i S w zależności od zmian temperatury. Próbka 1 - dolomit cechsztyński.

Ciśnienie uszczelnienia $=2000 \mathrm{psi}$

Tablica 3. Moduły $v$ i $E$ dla próbki 1 w porównaniu z danymi literaturowymi

\begin{tabular}{|l|c|c|l|}
\hline \multicolumn{1}{|c|}{ Skała } & $v[-]$ & $E[\mathrm{GPa}]$ & \multicolumn{1}{c|}{ Uwagi } \\
\hline $\begin{array}{l}\text { Dolomit cechsztyński o dużej } \\
\text { porowatości }(18,42 \%)\end{array}$ & $0,22 \div 0,25$ & $25,1 \div 29,8$ & $\begin{array}{l}\text { Przedział wyników w zależności od temperatury i ciśnienia uszczelnienia } \\
\text { podczas badania } \\
\text { Wysoka zawartość gazu w przestrzeni porowej obniża moduły sprężystości }\end{array}$ \\
\hline $\begin{array}{l}\text { Dolomity, anhydryty } \\
\text { cechsztyńskie KG-1 [2] }\end{array}$ & 0,28 & 80,0 & $\begin{array}{l}\text { Wartości średnie dla 44 próbek } \\
\text { Skały zbite }\end{array}$ \\
\hline
\end{tabular}

\section{Próbka 2 - piaskowiec kredy górnej o wysokiej zawartości mineratów ilastych}

Pomiary z użyciem próbki 2 również były wykonywane w stanie suchym. W pierwszym kroku przy ciśnieniu atmosferycznym stopniowo podnoszono temperaturę do wartości złożowej, tj. $83^{\circ} \mathrm{C}$. W kolejnym kroku przy stałej temperaturze $83^{\circ} \mathrm{C}$ podnoszono ciśnienie uszczelnienia do wartości 6000 psi.

W pierwszym kroku prędkość fali P malała od $3820 \mathrm{~m} / \mathrm{s}$ do $3463 \mathrm{~m} / \mathrm{s}$, natomiast prędkość fali S nieznacznie zmniejszyła się - od 2010 m/s do 1997 m/s (rysunek 7). Stosunek $V_{p} / V_{s}$ jest dość wysoki i wskazuje na obecność minerałów ilastych w próbce [6]. Wraz ze wzrostem temperatury obniżał się od 1,92 do 1,75. Moduł Younga zmniejszył się od

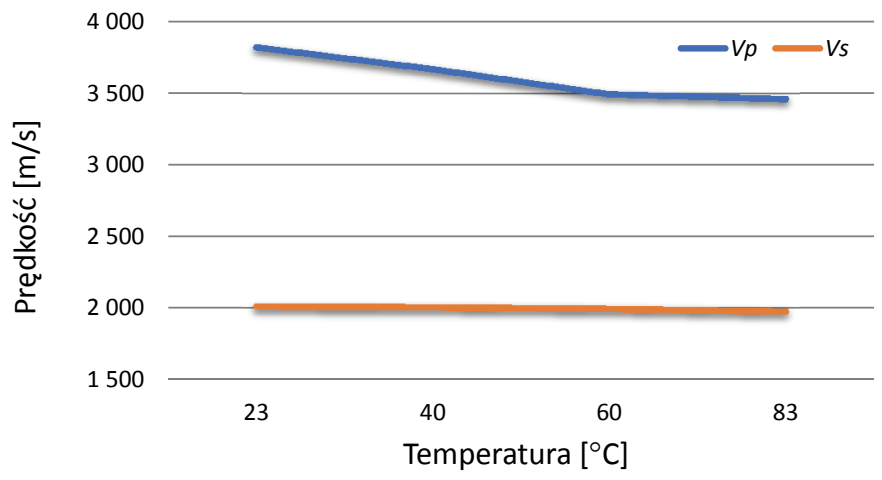

Rys. 7. Zmiany prędkości fal P i S w zależności od zmian temperatury. Próbka 2 - piaskowiec kredy górnej.

Ciśnienie uszczelnienia $=0 \mathrm{psi}$
28,3 GPa do 26,3 GPa (rysunek 8), a współczynnik Poissona od 0,31 do 0,26 (rysunek 9). M. Bała [2] dla piaskowców kredy górnej (cenoman), nasyconych gazem z otworu $\mathrm{L}-28$, podaje wartości $v_{s r}=0,17$, natomiast moduł $E_{s r}$ wynosi $35 \mathrm{GPa}$ (tablica 4). Badana próbka ma wyższy współczynnik $v$, ponieważ może posiadać niższy współczynnik porowatości i mniej gazu w przestrzeni porowej. Może też zawierać więcej minerałów ilastych (stąd nieco niższy moduł $E$ ).

W drugim kroku przy podnoszeniu ciśnienia uszczelnienia prędkości fal P i S rosły (rysunek 10). Wzrost ciśnienia uszczelnienia, zgodnie z danymi literaturowymi [8, 16], spowodował wzrost modułów $E$ oraz $v$ (rysunki 11, 12).

Zgodnie z literaturą [17] skałę można nazwać perspektywiczną do przeprowadzenia zabiegu szczelinowania, gdy mo-

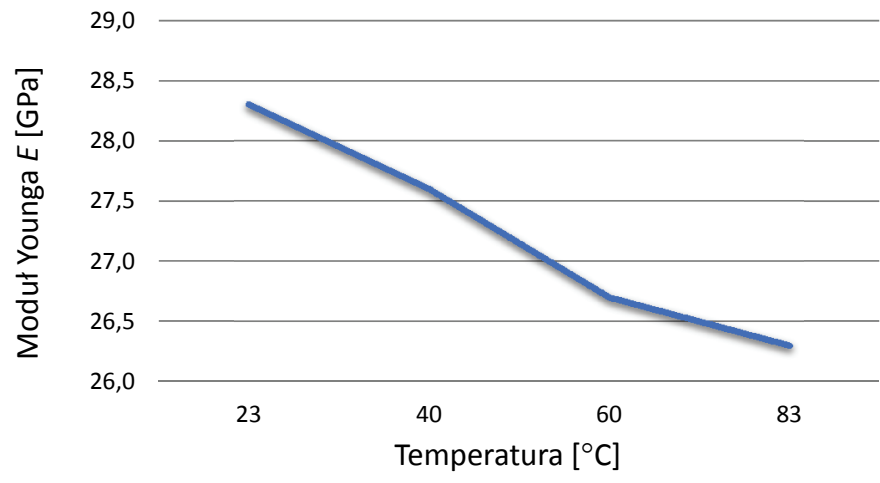

Rys. 8. Zmiany wartości modułu Younga w zależności od zmian temperatury. Próbka 2 - piaskowiec kredy górnej. Ciśnienie uszczelnienia $=0 \mathrm{psi}$ 


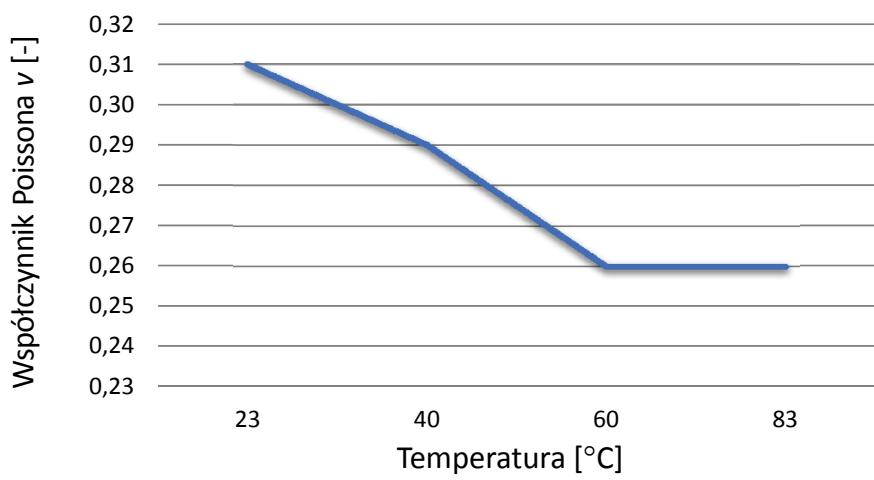

Rys. 9. Zmiany wartości współczynnika Poissona w zależności od zmian temperatury. Próbka 2 - piaskowiec kredy górnej. Ciśnienie uszczelnienia $=0$ psi

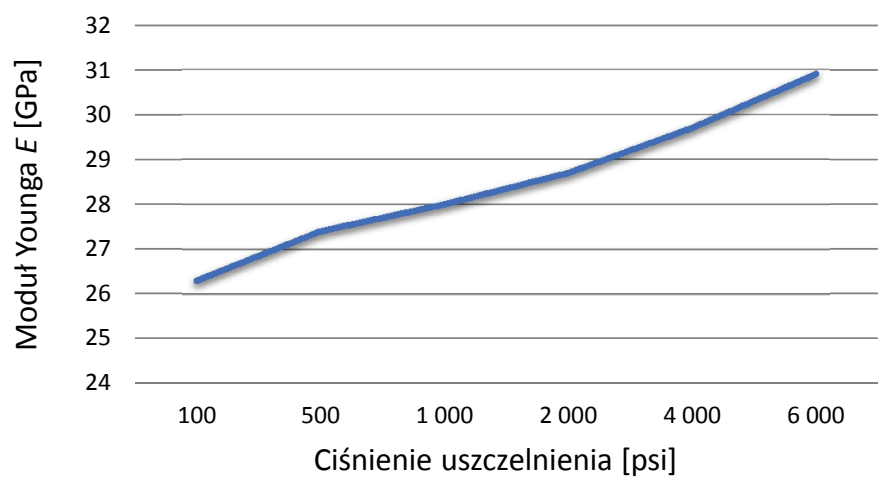

Rys. 11. Zmiany wartości modułu Younga w zależności od zmian ciśnienia uszczelnienia. Próbka 2 - piaskowiec kredy górnej. Temperatura $=83^{\circ} \mathrm{C}$

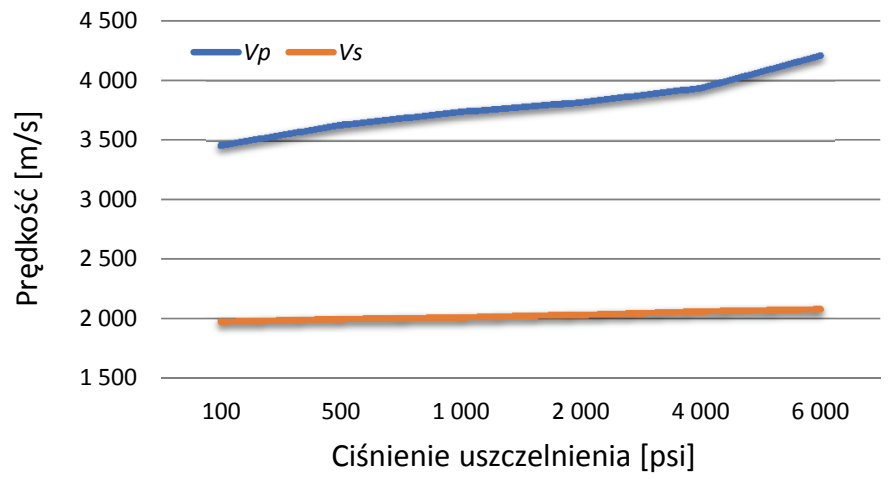

Rys. 10. Zmiany prędkości fal P i S w zależności od zmian ciśnienia uszczelnienia. Próbka 2 - piaskowiec kredy górnej. Temperatura $=83^{\circ} \mathrm{C}$

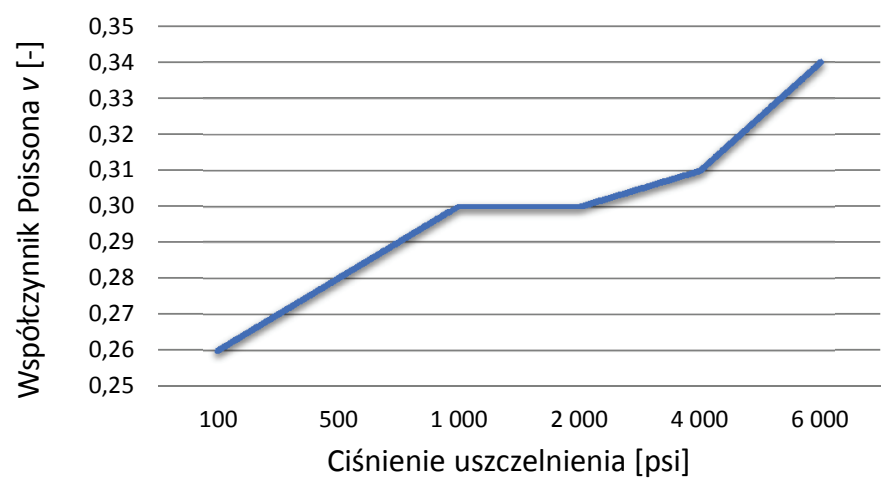

Rys. 12. Zmiany wartości współczynnika Poissona w zależności od zmian ciśnienia uszczelnienia.

Próbka 2 - piaskowiec kredy górnej. Temperatura $=83^{\circ} \mathrm{C}$

Tablica 4. Moduły $v$ i $E$ dla próbki 2 w porównaniu z danymi literaturowymi

\begin{tabular}{|l|c|c|l|}
\hline \multicolumn{1}{|c|}{ Skała } & $v[-]$ & $E[\mathrm{GPa}]$ & \multicolumn{1}{c|}{ Uwagi } \\
\hline $\begin{array}{l}\text { Piaskowiec kredy górnej. Wysoka } \\
\text { zawartość minerałów ilastych }\end{array}$ & $0,26 \div 0,34$ & $26,3 \div 30,9$ & $\begin{array}{l}\text { Przedział wyników w zależności od temperatury i ciśnienia uszczel- } \\
\text { nienia podczas badania } \\
\text { Minerały ilaste podwyższają współczynnik Poissona }\end{array}$ \\
\hline $\begin{array}{l}\text { Piaskowce, kreda, cenoman, } \\
\text { nasycone gazem Ł-28 [2] }\end{array}$ & 0,17 & 34,9 & Wartości średnie dla 5 próbek \\
\hline
\end{tabular}

duł $E$ jest wyższy niż 24,1 GPa. Uzyskany moduł $E$ jest nieco wyższy, jednak dodając do tego wysoki $v$, można stwierdzić, że badana skała jest trudna do szczelinowania. W skale utworzyłaby się prawdopodobnie szczelina prosta, dwuskrzydłowa, a jej ściany przez dużą plastyczność mogłyby wykazywać tendencję do silnego zaciskania się. Ciśnienie szczelinowania podczas zabiegu w takiej skale jest wyższe niż w skałach bardziej kruchych. Koncentracja podsadzki musiałaby być stosunkowo wysoka, ilość podsadzki duża, a objętość cieczy zabiegowej mała.

\section{Próbka 3 - piaskowiec czerwonego spagowca}

Pomiary z użyciem próbki 3 były wykonywane w stanie suchym, a następnie przy nasyceniu solanką $2 \% \mathrm{KCl}$ oraz „martwą” ropą. W pierwszym kroku podwyższano temperaturę suchej skały do wartości złożowej $61^{\circ} \mathrm{C}$. Następnie próbkę nasycono solanką oraz podniesiono ciśnienie uszczelnienia do 2000 psi. W drugim kroku, przy stałym ciśnieniu uszczelnienia 6000 psi i stałej temperaturze $61^{\circ} \mathrm{C}$, podnoszono ciśnienie porowe do 5000 psi tak, aby obniżyć ciśnienie efektywne działające na szkielet skalny. Drugi krok badania powtórzono przy nasyceniu rdzenia „martwą" ropą naftową.

W pierwszym kroku (rysunek 13) w rdzeniu suchym podczas spadku temperatury prędkość fali P wynosiła od 2189 do $2128 \mathrm{~m} / \mathrm{s}$, a fali S od 1487 do $1476 \mathrm{~m} / \mathrm{s}$. Następnie po nasyceniu rdzenia solanką prędkość fali $\mathrm{P}$ gwałtownie podniosła się do wartości od $2780 \mathrm{~m} / \mathrm{s}$ i dalej rosła wraz ze wzrostem ciśnienia uszczelnienia. Prędkość fali S podwyższyła się tylko nieznacznie do $1577 \mathrm{~m} / \mathrm{s}$. Tym samym znacznie 
wzrósł stosunek $V_{p} / V_{s}$, z około 1,42 do 1,79 i więcej. Niski stosunek $V_{p} / V_{s}$ jest wskaźnikiem występowania gazu [24]. Obecność gazu silnie zmniejsza prędkość fali P, podczas gdy prędkość fali S obniża tylko nieznacznie [5]. Prędkość fali $\mathrm{P} \mathrm{w}$ skale nasyconej cieczą jest wyższa niż w skale suchej (nasyconej gazem), ponieważ moduł odkształcalności objętości $k$ cieczy jest wyższy niż moduł $k$ gazu [4]. Na rysunkach 14 i 15 można zaobserwować skokowy wzrost współczynnika Poissona i modułu Younga w momencie nasycenia próbki solanką. Moduły przed nasyceniem solanką są bardzo zaniżone przez obecność powietrza w przestrzeni porowej. M. Bała [2] przytacza wartości modułów sprężystości dla piaskowca czerwonego spągowca z otworu KG-1: $v_{s r}=0,21$, a $E_{s r}=63 \mathrm{GPa}$. Współczynnik Poissona odpowiada w przybliżeniu uzyskanym wartościom po nasyceniu solanką, natomiast moduł Younga w niniejszym opracowaniu jest niższy i wynosi maksymalnie do około $17 \div 19$ GPa. Może to być konsekwencją wyższego współczynnika porowatości

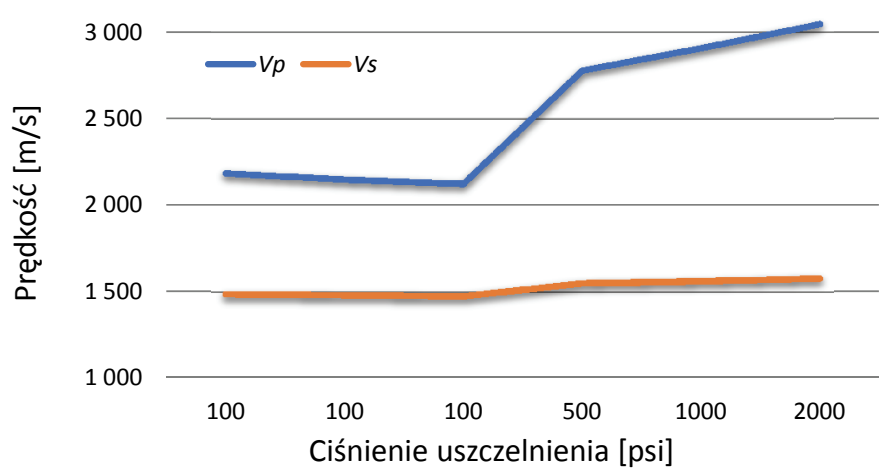

Rys. 13. Zmiany prędkości fal P i S w zależności od zmian ciśnienia uszczelnienia. Próbka 3 - piaskowiec czerwonego spągowca. Od ciśnienia uszczelnienia 500 psi - rdzeń nasycony solanką $2 \% \mathrm{KCl}$

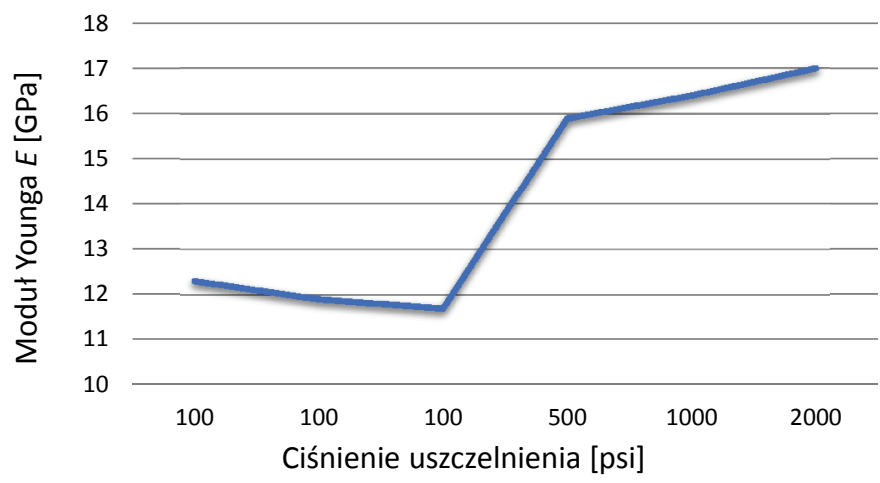

Rys. 15. Zmiany wartości modułu Younga w zależności od zmian ciśnienia uszczelnienia. Próbka 3 - piaskowiec czerwonego spągowca. Od ciśnienia uszczelnienia 500 psirdzeń nasycony solanką $2 \% \mathrm{KCl}$ efektywnej w badanej skale. Wartości modułów $E$ i $v$ uzyskane dla omawianej próbki znacznie bardziej odpowiadają wartościom dla silnie nasyconych piaskowców kredowych o wysokiej porowatości z otworu St-M1 [2] (tablica 5). Należy również pamiętać, że na parametry sprężyste ma wpływ nie tylko sama obecność gazu lub cieczy w porach, lecz także rozłożenie w przestrzeni porowej fazy gazowej oraz ciekłej, co opisuje Bała [5].

Podczas podnoszenia ciśnienia porowego (obniżania ciśnienia efektywnego) prędkości fal P i S, zarówno dla rdzenia nasyconego solanką, jak i ropą, malały (rysunek 16).

Niski moduł $E$ oraz współczynnik $v$ badanej próbki piaskowca czerwonego spągowca $\mathrm{w}$ stanie nasyconym pozwalają przypuszczać, że podczas zabiegu szczelinowania utworzyłaby się (podobnie jak w przypadku próbki 2) prosta szczelina dwuskrzydłowa z tendencją do zaciskania się. Cieczą zabiegową mogłaby być ciecz sieciowana z dużą ilością materiału podsadzkowego.

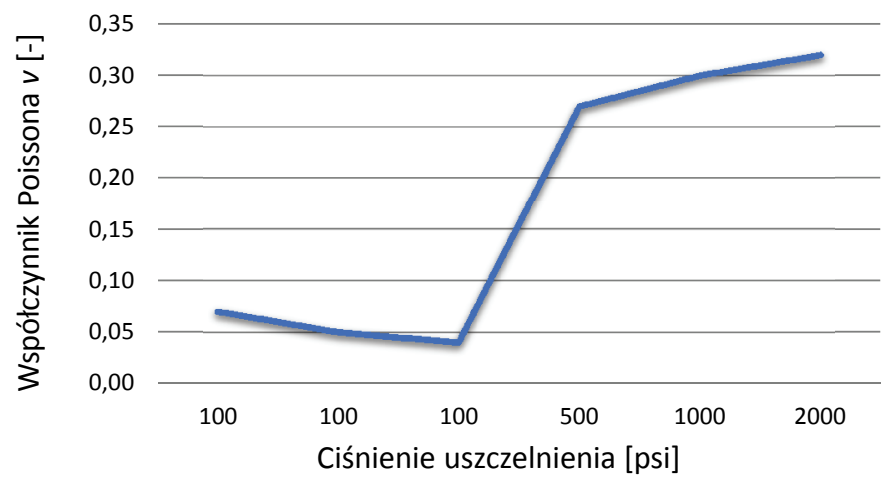

Rys. 14. Zmiany wartości współczynnika Poissona w zależności od zmian ciśnienia uszczelnienia. Próbka 3 piaskowiec czerwonego spągowca. Od ciśnienia uszczelnienia 500 psi - rdzeń nasycony solanką $2 \% \mathrm{KCl}$

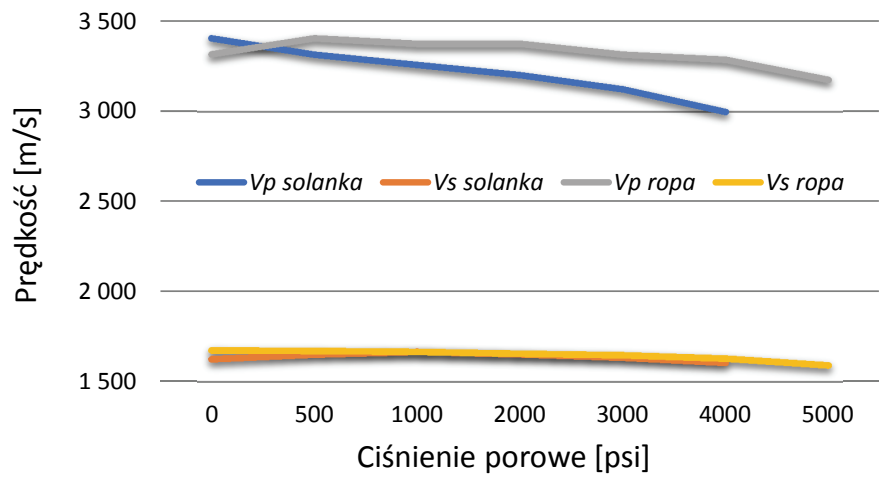

Rys. 16. Zmiany prędkości fal P i S w zależności od zmian ciśnienia porowego. Próbka 3 - piaskowiec czerwonego spągowca. Temperatura $=61^{\circ} \mathrm{C}$. Ciśnienie uszczelnienia $=6000 \mathrm{psi}$ 
Tablica 5. Moduły $v$ i $E$ dla próbki 3 w porównaniu z danymi literaturowymi

\begin{tabular}{|l|c|c|l|}
\hline \multicolumn{1}{|c|}{ Skała } & $v[-]$ & $E[\mathrm{GPa}]$ & \multicolumn{1}{c|}{ Uwagi } \\
\hline $\begin{array}{l}\text { Piaskowiec czerwonego spągowca } \\
\text { o dużej porowatości nasycony gazem } \\
\text { (powietrzem) }\end{array}$ & $0,04 \div 0,07$ & $11,7 \div 12,3$ & $\begin{array}{l}\text { Przedział wyników w zależności od temperatury podczas badania } \\
\text { Wysoka zawartość gazu w przestrzeni porowej obniża moduły } \\
\text { sprężystości }\end{array}$ \\
\hline $\begin{array}{l}\text { Piaskowce kredowe, cenoman, bardzo } \\
\text { dobrze nasycone gazem [2] }\end{array}$ & 0,09 & 16,8 & Wartości średnie dla 21 próbek \\
\hline $\begin{array}{l}\text { Piaskowiec czerwonego spągowca } \\
\text { o dużej porowatości nasycony solanką }\end{array}$ & $0,27 \div 0,34$ & $15,9 \div 18,3$ & $\begin{array}{l}\text { Przedział wyników w zależności od ciśnienia uszczelnienia } \\
\text { podczas badania } \\
\text { Zatłoczenie solanki powoduje wzrost modułów sprężystości }\end{array}$ \\
\hline $\begin{array}{l}\text { Piaskowiec czerwonego spągowca } \\
\text { o dużej porowatości nasycony } \\
\text { „martwą” ropą }\end{array}$ & $0,30 \div 0,33$ & $16,5 \div 19,2$ & $\begin{array}{l}\text { Przedział wyników w zależności od ciśnienia uszczelnienia } \\
\text { podczas badania }\end{array}$ \\
\hline $\begin{array}{l}\text { Piaskowce kredowe, cenoman, o dużej } \\
\text { porowatości, zawodnione [2] }\end{array}$ & 0,29 & 15,3 & Wartości średnie dla 19 próbek \\
\hline
\end{tabular}

\section{Podsumowanie i wnioski}

1. Niniejszy artykuł prezentuje wstępne, wybrane wyniki laboratoryjnych badań dynamicznych modułów sprężystości dla trzech próbek skał, z wybranych polskich złóż węglowodorów. Podczas badań wykonano szereg symulacji zmian warunków złożowych ciśnienia, temperatury i rodzaju medium złożowego oraz badano wpływ tych zmian na prędkości fal podłużnych i poprzecznych oraz dynamiczne moduły sprężystości. Uzyskane wyniki odniesiono do danych literaturowych.

2. Dynamiczne moduły sprężystości są w bardzo dużym stopniu uzależnione od współczynnika porowatości efektywnej skały. Przy pomiarach skał porowatych w stanie suchym prędkości fal $\mathrm{P}$ i S oraz moduły sprężystości $v$ i $E$ są obniżane za sprawą obecności powietrza w przestrzeni porowej skały. Nasycenie skały solanką lub „martwą” ropą powoduje wzrost prędkości fal oraz modułów sprężystości. Obecność minerałów ilastych w suchej próbce o niewielkiej porowatości powoduje podwyższenie współczynnika Poissona i obniżenie modułu Younga.

3. Urządzenie AVS-700, na którym wykonywane były badania, jest urządzeniem nowoczesnym i zaawansowanym technologicznie. Pozwala ono na uzyskiwanie precyzyjnych wyników pomiarów w symulowanych warunkach złożowych ciśnienia oraz temperatury. Wyniki te mogą być porównywane $\mathrm{z}$ danymi z profilowań akustycznych geofizyki otworowej i są bardzo przydatne w procesie projektowania i zabiegów hydraulicznego szczelinowania.

4. Niniejsza praca i jej wyniki powinny być odbierane jako wstępne zapoznanie się z tematyką pomiarów dynamicznych modułów sprężystości polskich skał zbiornikowych ropy i gazu w warunkach złożowych. Na prędkość fali akustycznej w skale (i tym samym na wartości modułów sprężystości) ma wpływ wiele parametrów, m.in.: rodzaj skały, jej gęstość i porowatość, rodzaj medium wypełniającego pory, lepkość i gęstość medium, ciśnienie efektywne, temperatura pomiaru, anizotropia skały, a także precyzja wykonania próbki oraz częstotliwość pracy nadajnika i odbiornika. W związku z tym, aby dobrze poznać wpływ warunków złożowych na cechy sprężyste skały z danego złoża, powinno się wykonać szereg badań, najlepiej na kilkudziesięciu próbkach z jednego złoża, jednocześnie koncentrując się przy tym na zmianach jednego z powyższych czynników oraz ograniczając wpływ pozostałych. Wyniki badań geoakustycznych powinny być odnoszone do wyników badań wytrzymałościowych (statycznych), a także mineralogicznych i petrograficznych badań próbek skalnych.

Prosimy cytować jako: Nafta-Gaz 2017, nr 2, s. 81-89, DOI: 10.18668/NG.2017.02.02

Artykuł nadesłano do Redakcji 29.11.2016 r. Zatwierdzono do druku 13.01.2017 r.

Artykuł powstał na podstawie pracy statutowej pt.: Wyznaczanie modułu Younga i współczynnika Poissona dla wybranych skał złożowych, pod kątem potrzeb hydraulicznego szczelinowania - praca INiG - PIB na zlecenie MNiSW; nr zlecenia: 32/KS, nr archiwalny: DK-4100-32/16. 


\section{Literatura}

[1] Ajufo A., Chapman D., Kier J.: Improved reservoir charakterization and delineation using acustic measurements on cores. Conference Materials Gas Technology Conference, Calgary, Canada 26.04-1.05.1996. SPE-35654-MS, s. 707-716.

[2] Bała M.: Klasyfikacja skat osadowych na podstawie ich modułów sprężystości wyznaczonych z obrazów falowych. Przegląd Geologiczny 1990, nr 12, s. 556-559.

[3] Bała M.: Określanie prędkości fal poprzecznych $\left(V_{s}\right)$ na podstawie danych geofizyki otworowej. Przegląd Geologiczny 2009, vol. 57, nr 12, s. 1057-1066.

[4] Bała M.: The Evaluation of the Influence of Various Parameters on the Velocity of Elastic Wave Propagation in a Rock Medium. Transport in Porous Media 1992, nr 9, s. 123-134.

[5] Bała M.: The influence of pore media distribution on the elastic parameters of rock in Miocene sediments (Carpathian Foredeep, Poland, B deposit). Geology, Geophysics \& Environment 2015, vol. 41, nr 2, s. 155-167.

[6] Bała M.: Wpływ obecności iłów, porowatości oraz nasycenia porów woda i gazem na parametry sprężyste skat zbiornikowych określanych na podstawie teoretycznych modeli ośrodków porowatych i danych geofizyki wiertniczej. Przegląd Geologiczny 2007, vol. 55, nr 1, s. 46-53.

[7] Bała M., Skupio R.: Wpływ ciśnienia i temperatury na ksztattowanie się parametrów sprężystych i gęstość mediów złożowych. Nafta-Gaz 2013, nr 12, s. 887-893.

[8] Bourbie T., Coussy O., Zinszner B.: Acoustic of porous media. Institut Francias du Petrole. Technip, Paris 1987, s. 175-242.

[9] Ciechanowska M., Matyasik I., Such P., Kasza P., Lubaś J.: Uwarunkowania rozwoju wydobycia gazu z polskich formacji łupkowych. Nafta-Gaz 2013, nr 1, s. 7-17.

[10] Czupski M., Kasza P., Wilk K.: Płyny do szczelinowania złóż niekonwencjonalnych. Nafta-Gaz 2013, nr 1, s. 42-59.

[11] Dziedzic A., Łukaszewski P.: Metodyczne uwarunkowania badań geomechanicznych skat pobranych z dużych głębokości, $w$ trójosiowym stanie naprężenia. Nafta-Gaz 2015, nr 1, s. 5-7.

[12] Dziedzic A., Łukaszewski P.: Pomiary fali ultradźwiękowej w badaniach trójosiowego ściskania. Górnictwo i Geoinżynieria 2010, rok 34, zeszyt 2, s. 1-8.

[13] Economides J., Nolte K.: Reservoir Stimulation. Third Edition. Schlumberger 2000, s. 3.1-3.34.

[14] Ellis D., Singer J.: Well Logging for Earth Scientists, 2nd Edition. Springer 2008, s. 479-568.

[15] Grieser B., Bray J.: Identification of Production Potential in Uncoventional Reservoirs. SPE Production and Operations Symposium, Oklahoma City, OK, USA, 31.03-3.04.2007, SPE 106623, s. 1-6.

[16] Jizba D.: Mechanical and acoustical properties of sandstone and shales. A dissertation. Stanford University 1991, s. $175-260$.

[17] Kasza P.: Efektywne szczelinowanie łupków w Polsce. Nafta-Gaz 2013, nr 11, s. 807-813.
[18] Kasza P.: Zabiegi hydraulicznego szczelinowania $w$ formacjach tupkowych. Nafta-Gaz 2011, nr 12, s. 874-883.

[19] Liana B.: Wyznaczanie parametru kruchości lupków dolnego paleozoiku basenu baltyckiego na podstawie danych otworowych. Wiadomości Naftowe i Gazownicze 2015, nr 10, s. $8-12$.

[20] Market J., Quirein J., Wicher J., Hinz D., Buller D., Al.-Dammad C., Spain D., Odumosu T.: Logging-WhileDrilling in Unconventional Shales. Conference materials SPE Annual Technical Conference and Exhibition, Florence, Italy 19-22.09.2010, SPE 122685, s. 1-18.

[21] Morcote A., Mavko G., Prasad M.: Dynamic elastic properties of coal. Geophysics 2010, vol. 75, nr 6, s. E227-E234.

[22] Moska R.: Metody geofizyki otworowej i ich wykorzystanie $w$ projektowaniu i przygotowaniu zabiegów hydraulicznego szczelinowania. Nafta-Gaz 2016, nr 1, s. 23-31, DOI: 10.18668/NG2016.01.03.

[23] Qiuliang Y., De-hua H.: Acoustic properties of coal form lab measurements. SEG Annual Meeting, Las Vegas, Nevada 9-14.11.2008, SEG-2008-1815, s. 1815-1817.

[24] Rickman R., Mullen M., Petre E., Greiser B., Kundert D.: A practical Use of Shale Petrophysics for Stimulation Designing Optimalization: All Shale Plays Are Not Clones of the Barnett Shale. Conference Materials SPE Annual Technical Conference and Exhibition, Denver, Colorado, USA, 21-24.09.2008, SPE 115258, s. 3-4.

[25] Tatham R.: $V_{p} / V_{s}$ and litology. Geophysics 1982, vol. 41, $\mathrm{nr} 3$, s. 336-344.

[26] Toksoz M., Cheng C., Timur A.: Velocities of seismic waves in porous media. Geophysics 1976, vol. 41, nr 4, s. 837-849.

[27] Tutuncu A., Sharma M.: Relating static and ultrasonic laboratory measurement to acoustic rock measurements in thight gas sands. Conference materials SPE Annual Technical Conference and Exhibition, Washington, DC, USA, 4-7.10.1992, SPE-24689-MS, s. 299-311.

[28] Winkler K.W., Murphy W.F.: Acoustic Velocity and Attenuation in Porous Media. Rock Physics and Phase Relations: A Handbook of Physical Constants 1995, s. 21-34.

[29] Zorski T., Jarzyna J., Derkowski A., Środoń J.: Geofizyka otworowa $w$ dobie poszukiwań gazu w tupkach - przeglad metod pomiarowych. Przegląd Geologiczny 2013, tom 61, s. $424-434$.

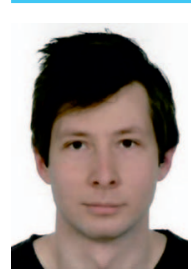

Mgr Rafał MOSKA

Asystent w Zakładzie Stymulacji Wydobycia Węglowodorów.

Instytut Nafty i Gazu - Państwowy Instytut Badawczy ul. Lubicz 25 A

31-503 Kraków

E-mail: rafal.moska@inig.pl 